\title{
Mecanismos de governança em universidades sem fins lucrativos: um ensaio teórico
}

\author{
Djeison Siedschlag (D) @ \\ Jeferson Lana (1) @ \\ Universidade do Vale do Itajaí (UNIVALI), Brasil
}

\begin{abstract}
Resumo. Este ensaio teórico teve como objetivo compreender a dinâmica dos mecanismos de governança corporativa para as universidades sem fins lucrativos. 0 estudo foi realizado por meio de um ensaio teórico, de natureza reflexiva e interpretativa, buscando aprofundar a temática com base em articulações teóricas. Foi possível verificar a existência de conflitos de agência, contudo o tema governança corporativa para universidades sem fins lucrativos é incipiente e faltam estudos que desenvolvam a temática no segmento do ensino superior, em especial para universidades sem fins lucrativos, que têm vivenciado significativas transformações no seu modelo de gestão em face da crescente competitividade no setor, do intenso processo de regulação pelas políticas educacionais e das mudanças na relação com o conhecimento. Os resultados demonstram que a adoção de mecanismos de governança corporativa pelas universidades sem fins lucrativos pode contribuir para atenuar conflitos de agência, embora a teoria da agência desenvolva a relação (conflitos) em organizações de capital aberto com finalidade de lucro, no contexto das universidades sem fins lucrativos contata-se, além do conflito entre principal e agente, o conflito de agência entre gestores e stakeholders.
\end{abstract}

Palavras-chave: governança corporativa; mecanismos de governança corporativa; universidades sem fins lucrativos.

\section{Mecanismos de gobernanza en universidades sin fines de lucro: un ensayo teórico}

Resumen. Este ensayo teórico tiene como objetivo comprender la dinámica de los mecanismos de gobernanza corporativa en las universidades sin fines de lucro. Se ha realizado el estudio por medio de un ensayo teórico, de carácter reflexivo e interpretativo, que busca profundizar la temática con base en articulaciones teóricas. Se ha podido comprobar la existencia de conflictos de agencia, pero el tema de la gobernanza corporativa en universidades sin fines de lucro resulta incipiente y faltan estudios que desarrollen la temática en la educación superior, sobre todo en las universidades sin fines de lucro, que han experimentado transformaciones relevantes en su modelo de gestión frente a la creciente competitividad en el sector, el intenso proceso de regulación por las políticas educativas y los cambios en la relación con el conocimiento. Los resultados muestran que los mecanismos de gobernanza corporativa adoptados por las universidades sin fines de lucro pueden contribuir a mitigar conflictos de agencia, aunque la teoría de la agencia desarrolle la relación (conflictos) en organizaciones de capital abierto con fin de lucro, en el ámbito de las universidades sin fines de lucro se comprueba, además del conflicto entre principal y agente, el conflicto de agencia entre gestores y stakeholders.

Palabras clave: gobernanza corporativa; mecanismos de gobernanza corporativa; universidades sin fines de lucro.

\section{Governance mechanism in non-profit universities: theoretical essay}

Abstract. This theoretical essay aimed to understand the dynamics of corporate governance mechanisms for nonprofit universities. The study was conducted through a theoretical essay, reflective and interpretative in nature, seeking to deepen the theme based on theoretical articulations. It was possible to verify the existence of agency conflicts, however the corporate governance theme for non-profit universities is incipient and there is a lack of studies that develop the theme in the higher education segment, especially for non-profit universities, which have experienced significant changes in their work. management model in the face of increasing competitiveness in the sector, the intense process of regulation by educational policies and changes in the relationship with knowledge. The results demonstrate that the adoption of corporate governance mechanisms by nonprofit universities can help mitigate agency conflicts, although agency theory develops the relationship (conflicts) in publicly-traded, profit-making organizations in the context of non-profit universities. For profit purposes, in addition to the conflict between principal and agent, the agency conflict between managers and stakeholders is contacted.

Keywords: corporate governance; corporate governance mechanisms; nonprofit universities. 


\section{Introdução}

0 rápido crescimento do segmento educacional, com uma nova tipologia, que passou a se chamar setor privado na educação superior, acirrou a concorrência, antes quase inexistente, entre as instituições de ensino superior (IES). 0 setor passou a focar no gerenciamento de resultados, ficando a atuação governamental restrita ao campo da avaliação, como alternativa de regulação do novo setor. Este se configurou rapidamente, graças a um processo relativamente facilitado de autorização de funcionamento de faculdades, centros universitários e universidades privadas.

Neste contexto, a educação superior no Brasil passou a acomodar, além das instituições públicas, as privadas (com e sem fins lucrativos), estas últimas resultantes do agrupamento de atores com diferentes formatos jurídicos e finalidades econômicas, compondo um conjunto bastante diversificado e diferenciado em seus fins e na própria concepção de universidade. Tudo isso com evidentes diferenças no modelo de governança adotado pelas IES e com reflexos na forma de administração acadêmica, nas relações com o aluno e com seu corpo docente e técnico-administrativo, bem como na forma de inserção dessas universidades no meio social onde atuam (Tavares, 2009). Contudo, segundo Jung, Fossatti e Monticelli (2019), falta a capacidade de governança para garantir que as universidades ofereçam as respostas inovadoras e empreendedoras necessárias para os dias atuais. Nesse sentido, o sistema de governança das instituições de ensino também se torna um ponto importante dentro da análise da governança dos sistemas educacionais. Como doravante explicado, aspectos como sistema legal e estrutura de propriedade e controle ajudam a definir o encaminhamento do sistema educacional de determinado país.

A governança corporativa - GC tornou-se um tema discutido no campo de instituições de ensino superior com grande impacto acadêmico e prático. Para Kreuzberg e Vicente (2019), as pesquisas voltam-se à compreensão de fenômenos pela análise interligada da teoria da agência, teoria dos stakeholders, stewardship e dependência de recursos.

No segmento educacional as pesquisas têm focado na aplicação das boas práticas de governança corporativa. Segundo Grings e Vier (2019), as instituições de ensino superior estão vivendo uma fase de transformação na busca da profissionalização do seu quadro diretivo para atender às boas práticas, convergindo aos modelos praticados nos maiores grupos educacionais presentes no mercado brasileiro, em que a GC tem expressiva importância. Assim, a análise dos mecanismos de governança pode contribuir para o aprimoramento da gestão e governança de universidades sem fins lucrativos. A implementação de mecanismos de GC em IES parece ser inquestionável, 
embora o ritmo da adoção de práticas de GC irá variar dependendo do país (Taylor, 2012). No Brasil, há apenas seis estudos que citam os mecanismos externos de GC, mas apenas um deles operacionaliza esses mecanismos empiricamente (Bueno, et al., 2018). Os autores argumentam que embora os mecanismos externos sejam importantes, apenas nos últimos anos as pesquisas têm evidenciado a sua importância e a necessidade de reconhecê-los e de saber usá-los a seu favor.

Há, na literatura, seis mecanismos que se originam fora da empresa e que ajudam a garantir que os executivos respeitem os direitos e os interesses da empresa e atuem de forma transparente: sistema legal, mercado para o controle corporativo, auditoria externa, agências de rating, ativismo dos stakeholders e mídia (Aguilera et al., 2015). Todavia, tais mecanismos externos de governança foram desenvolvidos para empresas, em geral, de capital aberto, e não se verificam pesquisas que analisam estes mecanismos no contexto de universidades sem fins lucrativos, sendo esta uma contribuição teórica e prática deste estudo.

Estudos recentes identificam o ativismo de stakeholders como potencial fator para a assimetria de informação entre acionistas, gestores e partes interessadas. Para Lee, Mcnamara e Koo, (2019), o ativismo ganhou popularidade na última década como um mecanismo de governança emergente para responder às preocupações da agência, forçando as empresas a alterar as suas estratégias e tomar ações que maximizem valor para o acionista. Desta forma, compreender a dinâmica dos mecanismos de governança corporativa para as universidades sem fins lucrativos é o objetivo geral deste estudo.

Para a construção deste ensaio teórico, optou-se por busca avançada nas seguintes bases de dados: SCOPUS, Web of Science, Google Scholar, SciELO e Portal de Periódicos da Capes. As principais palavras-chave da investigação foram: "governança corporativa"; "mecanismos de governança corporativa"; "universidades sem fins lucrativos". Não obstante, a busca também resultou em ampliação da literatura por meio dos artigos analisados. Assim foram selecionados os 12 principais artigos que desenvolveram a governança em IES e realizado analise em profundidade destes manuscritos. 


\section{Revisão teórica}

Para o desenvolvimento deste estudo buscou-se realizar a revisão teórica sobre a teoria da agência, gestão em universidades sem fins lucrativos, governança corporativa em IES e os mecanismos de governança corporativa. Por meio desta revisão teórica propõe-se os mecanismos de governança para IES sem fins lucrativos.

\section{Teoria da Agência}

No tocante a teoria da agência a seguir resgata-se os principais conceitos e problemáticas em foco. Todavia há evidências crescentes de que este fenômeno está se tornando relevante universidades sem fins lucrativos. A estrutura de controle e de gestão das organizações tem sido alterada na medida em que ocorrem mudanças no ambiente externo. A partir do momento em que aparecem dois papéis dentro de uma organização, emergem alguns problemas, entre os quais a adequação das decisões tomadas pelo administrador com as necessidades do acionista e de stakeholders, problema este que é estudado pela teoria da agência.

A teoria da agência enfatiza que no estabelecimento de um contrato considera-se que 0 agente e principal agem segundo comportamento racional e motivados por interesses próprios. Não se apoia, porém, exclusivamente nas diferenças de motivação e objetivos entre principal e agente, mas também em premissas de assimetria de informação, distinta tolerância ao risco e diferente horizonte de planejamento entre as partes, que implicam a racionalidade limitada dos agentes econômicos (Eisenhardt, 1989).

Segundo a ótica de Mendes (2001), a teoria da agência analisa os conflitos e custos resultantes da separação entre propriedade e controle de capital. Nesta mesma linha, Arruda, Madruga e Freitas (2008) destacam que "essa possibilidade de não participação do acionista no gerenciamento da empresa é bem representada pela sociedade por ações, que limita a responsabilidade do acionista para com a organização à parcela de capital que ele investiu".

Para Jensen e Meckling (1976) uma relação de agência é definida como sendo um contrato em que uma ou mais pessoas (principal) emprega outra pessoa (o agente) para realizar algum serviço ou trabalho em seu favor, envolvendo a delegação de alguma autoridade de decisão para o agente. 
Complementa ainda que, se ambas as partes são maximizadoras de utilidade, existe uma boa razão para acreditar que o agente não irá atuar conforme os interesses do principal.

Segundo o Instituto Brasileiro de Governança Corporativa - IBGC (2019), a hipótese fundamental é a que agente e principal são pessoas diferentes e, sendo assim, os interesses daquele que administra a propriedade nem sempre estão alinhados com os de seu titular. Dessa forma, no "conflito de agência", ocorre a incongruência entre o comportamento desejado pelo principal e o apresentado pelo agente.

Para Weston e Brigham (2004), os principais conflitos de agência são:

- Entre acionistas e administradores: os interesses dos administradores devem visar ao atendimento dos interesses dos acionistas, mas, muitas vezes, isso não ocorre e acaba originando um conflito de interesses entre as partes. Vários mecanismos podem ser utilizados para motivar os gerentes a agirem de acordo com os interesses dos acionistas, entre eles estão a ameaça de demissão, a ameaça de tomada de controle e a compensação administrativa;

- Entre acionistas e credores: os credores emprestam recursos à empresa com taxas baseadas no risco dos ativos existentes na firma, nas expectativas referentes ao risco de futuras adições de ativos, na estrutura existente de capital da empresa (quantia de financiamento da dívida que ela utiliza) e nas expectativas referentes às mudanças da estrutura de capital.

Outro tipo de conflito potencial relacionado à estrutura de capital da empresa, e relevante na realidade do mercado de capitais brasileiro, é constituído pelas divergências de interesses entre acionistas minoritários e acionistas majoritários. Apesar de Weston e Brigham (2004) apontarem dois conflitos na empresa, credores e acionistas e gestores e acionistas, não se pode considerar que existe perfeita convergência de interesses entre acionistas controladores e minoritários. De forma ainda mais abrangente, a conduta dos gestores em relação à decisão de qual grupo de interesse deve ser defendida, minoritários ou controladores, pode criar novos níveis de conflito de interesses. Como exemplo pode ser citada a possibilidade de proteção pelo gerente dos interesses do grupo de controle, que possui o poder de elegê-lo e destituílo. Assim, os acionistas majoritários, a partir de determinada concentração da propriedade (direito a voto) passam a perseguir, por hipótese, benefícios privados à custa dos demais investidores. 
Assim, a importância de um sistema de governança corporativa fortalecido, dotado de um conjunto de boas práticas de governança e de um conselho de administração bem estruturado, tem sido destacada como relevante para o alinhamento de interesses entre propriedade e controle (Brandão e Crisóstomo, 2015).

Tendo como concreto que os estudos sobre teoria da agência discutem, em grande medida, os conflitos existentes entre acionistas (principal) e gestores (agente), pode-se realizar a extrapolação desses conceitos para uma entidade sem finalidade lucrativa, onde sua ocorrência pode ser observada pelos embates acerca de seus direcionamentos de ações, formato de gestão ou ainda modelos de investimentos dos recursos disponíveis (Ávila e Bertero, 2016).

Os autores contribuem ainda para a discussão de problemas de agência em entidades do terceiro setor, em que os envolvidos nos rumos das instituições podem apresentar interesses díspares, havendo a possibilidade do surgimento de conflitos de agência e prejuízos ao cumprimento dos objetivos e finalidades para os quais foram criadas.

\section{Gestão em universidades sem fins lucrativos}

Se por um lado, o desafio para organizações com finalidade de lucro é mitigar conflitos de agência e atingir os objetivos traçados, por outro lado, a complexidade na gestão de universidades sem fins lucrativos estabelece desafios adicionais. A universidade pode ser entendida como uma organização complexa, pois reúne diversas áreas do conhecimento, diversos cursos, em diferentes níveis, lugar onde as decisões são essencialmente colegiadas e políticas e onde atuam profissionais altamente qualificados, formando grupos de interesse distintos (Meyer Jr. e Mangolim, 2006). Neste sentido, para Silva Jr (2006), a gestão universitária como área de estudo, disciplina e prática gerencial tem assumido posição de destaque no contexto da ciência da administração, em razão de sua especificidade no campo de estudos sobre as organizações universitárias.

Todavia, tal constatação não é recente, segundo Baldridge (1971) a divergência de opiniões, a defesa dos grupos de interesse e o uso do poder, forma o que é chamado de Modelo Político na gestão deste tipo de IES. A problemática pode estar relacionada a forma e modelo de gestão, conforme Lopes e Bernardes (2005) o problema de estruturação administrativa das IES, e em especial, das universidades sem fins lucrativos, reside na busca de um 
modelo que atenda às suas especificidades, que são originadas no pluralismo político e ideológico, que produz divergências, inclusive, no entendimento do projeto pedagógico e forma do ensino e aprendizagem.

Para Meyer Jr. e Lopes (2015), alguns elementos identificam a complexidade destas IES, como ambiguidade dos objetivos, tecnologia indefinida, grupos de interesse, poder compartilhado e a imensurabilidade do valor agregado. Esses elementos dispersos, porém, inter-relacionados, contribuem para a complexidade organizacional, constituindo, ao mesmo tempo, barreiras às práticas gerenciais tradicionais (Meyer Jr.; Lopes, 2015). Para Meyer Jr. e Lopes (2015), um dos maiores desafios dos administradores universitários é a adoção de uma gestão que envolva múltiplas variáveis decorrentes de sua complexidade, em especial aquelas de caráter subjetivo e de difícil mensuração. Sobretudo, a exigência de gestores capazes de combinar, em suas práticas, arte e ciência, racionalidade e intuição, criatividade e inovação, com coragem e sensibilidade suficientes para tomar decisões que não necessariamente encontram respaldo nos modelos racionais importados do setor empresarial (Meyer Jr. e Lopes, 2015).

Para Amarante et al. (2016), as universidades não buscam somente legitimar-se no contexto em que estão inseridas, elas buscam sua eficiência interna e dessa forma, responderem estrategicamente ao meio, indo além da simples conformidade. Entretanto, é preciso considerar, segundo Silva Jr (2006), que as IES têm, em função de imperativo legal, estrutura e dinâmica que as configuram como um sistema composto por dois subsistemas autônomos e independentes, porém complementares e dissociados: a entidade mantenedora e a entidade mantida, que representam, respectivamente, as estruturas de propriedade e de direção. A junção dessas características em um só tipo de organização potencializa a complexidade que ambas isoladamente já possuem.

Desta forma o autor complementa que a perspectiva de governança corporativa é mais ampliada do que a simples relação entre a propriedade e a direção, e a preservação dos interesses dos acionistas. Trata-se de uma perspectiva que envolve um sistema de valores que rege as corporações, em que justiça, transparência e responsabilidade corporativa são fundamentais para resguardar os interesses do negócio, dos stakeholders e da sociedade como um todo.

Tendo como base a regulamentação governamental, as IES privadas, por força de imperativo legal, apresentam em sua estrutura duas entidades distintas, porém complementares: a mantenedora e a mantida. Cada uma 
das entidades que formam uma IES tem características, funções e papéis próprios, que se completam e determinam a dinâmica institucional, conforme ilustrado na Figura 1.

Figura 1. Modelo da Estrutura e da Dinâmica da IES Privada

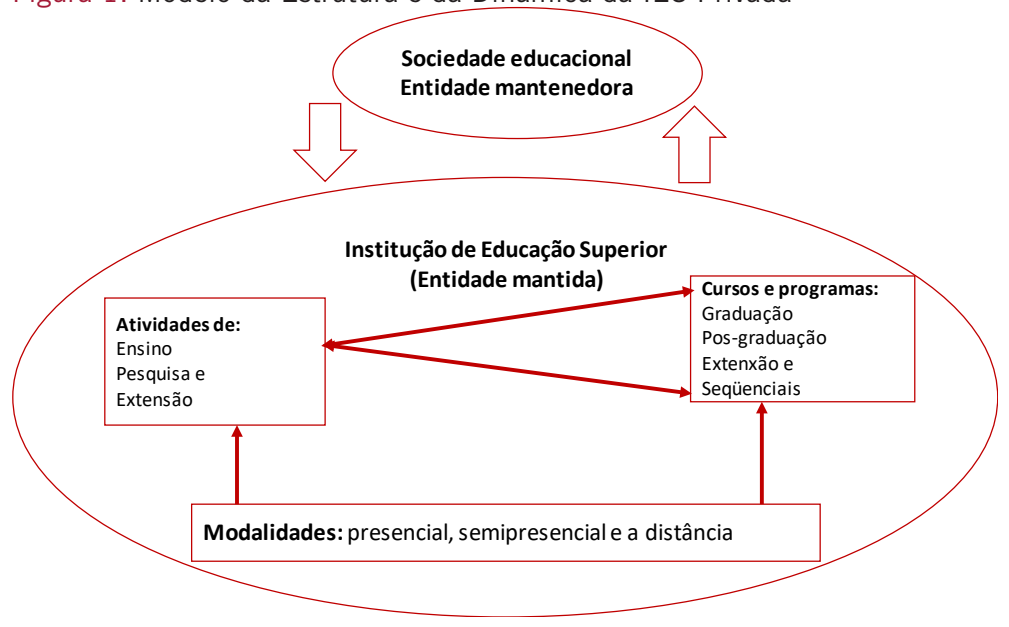

Fonte: Silva Jr (2006).

Em síntese, no exercício de sua função, as IES têm uma dinâmica própria e específica e prestam seus serviços educacionais por meio da oferta de cursos e programas de graduação, de pós-graduação (lato e stricto sensu), de extensão, sequenciais, nas modalidades presencial, semipresencial e a distância, por meio de atividades de ensino, pesquisa, extensão e prestação de serviços.

Segundo Silva Jr (2006), no processo de gestão universitária, a mantenedora e a mantida tomam decisões conjuntas e isoladas. As decisões de natureza estratégica, via de regra, são tomadas conjuntamente, pois envolvem questões de natureza jurídica, administrativa, financeira e acadêmica, ou seja, envolvem interesses da estrutura de propriedade e de direção.

\section{Governança corporativa em Instituições de ensino}

Apesar de pesquisas apontarem a complexidade na gestão de universidades, a temática de governança corporativa em IES é incipiente. Isso porque o conceito de governança corporativa está associado a organizações de capital aberto. 
Para Denis (2001), os problemas associados à separação de propriedade e controle pode ser considerado o principal evento da governança corporativa. Assim, o principal marco para a área foi o estudo de Jensen e Meckling (1976) ao aplicar a teoria da agência para as organizações modernas e formalizando o modelo de custos de agência do capital externo (Denis, 2001).

A partir de então, pesquisadores, principalmente sob um viés financeiro, investem esforços para compreender, mensurar e minimizar tais conflitos de interesse. Denis, (2001) e Daily et al. (2003) definem a GC como um conjunto de mecanismos institucionais e de mercado que induzem a gestão para comportamentos cujos interesses próprios de maximizar valor sobrepõem os interesses da organização. Para o IBGC (2019) a governança corporativa é definida como um sistema de direção, monitoramento e incentivo das organizações, que envolve diversas partes interessadas, como sócios, conselhos, diretoria e órgãos de fiscalização. As boas práticas desse sistema são capazes de beneficiar a organização de diversas formas, contribuindo com o seu valor econômico e qualidade de gestão.

Segundo Andrade e Rossetti (2007), historicamente as práticas de governança corporativa vêm se consolidando voltadas principalmente às empresas de capital aberto, porém sua diversidade permite que ela seja aplicável também aos demais tipos e portes de empresas.

Neste contexto, a pesquisa sobre métrica de governança corporativa: Os Caminhos Trilhados pelas Empresas de Capital Fechado desenvolvida pelo IBGC (2019) cumpre importante papel na temática da governança, preenchendo lacuna pouco explorada. Além disso, busca o objetivo de inspirar as empresas de capital fechado (com ou sem fins lucrativos) a evoluírem sua governança.

Figura 2. Percentual de participantes por estágio de maturidade

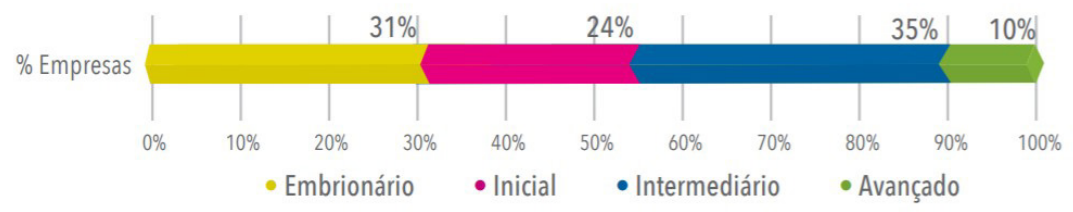

Fonte: IBGC - Métrica de Governança Corporativa: Os Caminhos Trilhados pelas Empresas de Capital Fechado, 2019.

Verifica-se que 90\% das empresas estão reunidas nos estágios embrionário, inicial ou intermediário; aquelas no nível avançado constituem grupo relativamente restrito, correspondendo a $10 \%$ da amostra. Neste universo encontram-se as instituições do terceiro setor, entidades privadas, de capital 
fechado sem fins lucrativos, que prestam serviços públicos (BNDES, 2001). No terceiro setor encontram-se as IES, universidades constituídas na forma de fundações sem fins lucrativos pela entidade mantenedora e mantidas.

Para Silva Jr (2006), a exemplo do que ocorre nas sociedades anônimas brasileiras, em que os interesses de propriedade são defendidos pelo conselho de administração, nas entidades mantenedoras, apesar de não ser legalmente obrigatório, é muito comum a presença de um conselho de mantenedora (formado por conselheiros internos e externos) para defender e assegurar os interesses dos sócios instituidores.

Já as entidades mantidas (centros acadêmicos), que representam a estrutura de direção (gestão estratégica, tática e operacional), apresentam estrutura hierárquica própria, com autoridade e responsabilidade para desempenhar atividades de natureza acadêmica, sem gozar de direitos de propriedade e de responsabilidade jurídica. Podem assumir qualquer uma das seguintes formas: universidades, centros universitários, faculdades integradas e faculdades isoladas, institutos superiores ou escolas superiores, institutos superiores de educação e centros de educação tecnológica.

Para Ávila e Bertero (2016), as fundações constituídas para a prestação de serviços específicos, normalmente têm como atribuição dos instituidores a sua subsistência, manutenção e crescimento, por meio do autofinanciamento, em que a gestão de recursos é realizada nos moldes de qualquer outra instituição privada. Todavia, pesquisas que tratam a governança corporativa em Instituições de Ensino Superior (IES) são recentes. No Quadro 1, são apresentados estudos sobre o tema governança corporativa em IES.

Quadro 1. Pesquisas de governança corporativa em IES

\begin{tabular}{ll}
\hline \multicolumn{1}{c}{ Autor } & \multicolumn{1}{c}{ Pesquisa/Resultados } \\
\hline Santos (2008) & Os resultados apontam a existência de relações entre a governança \\
& corporativa na IES e seu desempenho. \\
\hline & "As universidades confessionais, \\
& vêm conquistando seu espaço de atuação e tem na governabili- \\
Tavares (2009) & dade um de seus principais desafios neste início do século XXI, \\
& mantidas por entidades com fins lucrativos." \\
\hline & Em termos de governança, os resultados sugerem que a boa \\
& governança corporativa é um fator secundário na influencia, \\
& atração e retenção de capital intelectual. No entanto, os resul- \\
& tados ilustram três áreas notáveis em relação as práticas de GC \\
& nas universidades: Divulgação e \\
Mulili e Wong (2011) & transparência, equidade nas políticas e integridade e confiança.
\end{tabular}


Autor

\begin{tabular}{l}
\hline \multicolumn{1}{c}{ Autor } \\
Vilela e Veloso (2014) \\
Canito,Tassigny e Almeida \\
(2014) \\
MacLennan, Semensato e \\
Oliva (2015)
\end{tabular}

Vilela (2016)

Vilela (2016)

Ávila e Bertero (2016)
$\begin{aligned} & \text { Dzięgiela e Wojciechowskab } \\ & \text { (2016) }\end{aligned}$

Mello e Silva (2018)

Grings e Vier (2019)

Para as instituições de ensino superior, elevar a qualidade do ensino e melhorar suas práticas de gestão, de modo a garantir sua longevidade e sua sustentabilidade perante a sociedade, somente se dará da melhor maneira possível através dos princípios da governança corporativa.

A análise dos dados permitiu identificar possibilidades de utilização e aprimoramento de importantes instrumentos de governança e gestão na fundação pesquisada, a exemplo da atuação mais efetiva dos conselhos (curador, executivo e fiscal).

Relacionaram práticas de governança corporativa com a respon-

e sabilidade social empresarial, e constataram que as IES, tanto com, quanto sem fins lucrativos, utilizam tais práticas com um enfoque denominado reativo.

Constatou que uma IES privada, mesmo não possuindo um sistema de governança corporativa estruturado, mas aplicando práticas que se aproximam dos princípios deste sistema, pode ter avanços e benefícios em sua gestão.

Propuseram um índice de governança corporativa baseado nos princípios de independência, prestação de contas e transparência, e aplicando ele em uma fundação de apoio universitário, constataram um impacto positivo em relação ao desempenho econômico e volume de operações

Mostram que universidades dos Estados Unidos, Reino Unido e Nova Zelândia, certificadas pela AACSB International (Associação para avanço de escolas de negócios), que certifica qualidade em escolas de negócios, respeitam em larga escala os princípios de responsabilidade social corporativa.

A entidade adota um grande número das práticas de governança corporativa propostas pelo IBGC, todavia, não segue recomendações específicas e primordiais quanto a GC.

Evidenciou-se que muitas recomendações já são praticadas nas instituições e constatou-se tendência à maior aderência às práticas de Governança Corporativa, visto o grau de importância atribuído pelos gestores às recomendações presentes nos questionamentos.

Os resultados mostram que as universidades colombianas podem ser classificadas em três modelos: presença predominante

Flórez-Parra et al. (2019) das características da parte interessada ou modelo colegiado; presença mais forte do modelo de gestão ou anglo-americana; e um terceiro modelo que toma elementos de ambos.

Fonte: Elaborado pelos autores, 2020.

Santos (2008) evidencia a existência de relações entre a governança corporativa na instituição de ensino superior e seu desempenho. Já Tavares (2009) destaca que as universidades confessionais, vêm conquistando seu espaço de atuação e tem na governabilidade um de seus principais desafios neste início do século XXI. Contudo, ao tratar das universidades confessionais, 0 autor sugere que um modelo de governança que considere suas especificidades está ainda por ser construído. 
Por outro lado, na pesquisa de Mulili e Wong (2011), os resultados sugerem uma relação positiva entre o capital intelectual e a governança corporativa de modo que, quanto maior for a GC maior é o capital intelectual retido pela universidade. Esta conclusão é corroborada por 71,1 por cento dos respondentes que indicaram que não tinham intenção seria de deixar sua universidade atual.

Vilela e Veloso (2014) argumentam que a governança corporativa possibilitou as empresas de capital aberto o ganho com uma melhor administração, organização da empresa, transparência de suas atividades perante seus stakeholders, resta neste momento às instituições de ensino superior desenvolver o seu modelo de governança corporativa buscando estas melhorias já alcançadas por outras organizações.

Nesta linha a pesquisa de Canito, Tassigny e Almeida (2014) permitiu identificar possibilidades de utilização e aprimoramento de importantes instrumentos de governança e gestão, a exemplo da atuação mais efetiva dos conselhos (curador, executivo e fiscal). Vilela (2016) corrobora com os benefícios da GC para as IES, e mesmo não possuindo um sistema de governança corporativa estruturado, mas aplicando práticas que se aproximam dos princípios deste sistema, pode ter avanços e benefícios em sua gestão.

Contudo, Grings e Vier (2019) identificam muitas recomendações, apesar de serem consideradas importantes, não são praticadas, o que ficou evidente nos quesitos código de ética, auditoria interna e plano de sucessão.

De forma geral, as pesquisas de governança corporativa em IES apresentam o tratamento de problemas de agência existentes entre gestores e stakeholders e a aplicação das boas práticas da governança corporativa na gestão das IES envolvendo a estrutura da mantenedora e mantidas. Todavia, pouco é explorado sobre os mecanismos internos e externos de governança corporativa para atenuar os problemas de agência. Em virtude disso o próximo tópico discorre sobre os mecanismos de governança corporativa e propõe uma análise ao contexto das instituições sem fins lucrativos.

\section{Mecanismos de governança corporativa}

As pesquisas que desenvolvem o tema governança corporativa destacam a utilização de mecanismos de controle e mitigação de conflitos. Os mecanismos de governança corporativa podem ser classificados em duas categorias: interno e externo. Os mecanismos internos são aqueles instituídos no ambiente interno da empresa, e os externos instituídos pelo mercado 
como um todo (ambiente externo). Segundo Bueno, et al. (2018), de forma a melhorar a GC e, com isso, reduzir os conflitos entre acionistas, funcionários e partes interessadas, são utilizados os mecanismos de governança, classificados como internos - gerados dentro da empresa - e como externos - gerados fora da empresa.

Para os autores, os mecanismos internos de governança são os mais citados na literatura, principalmente na nacional (Brasil), entre os quais o conselho de administração e a estrutura de participação acionária, no entanto, nem sempre os mecanismos internos são suficientes para assegurar a transparência e a boa governança, de modo que se faz necessário utilizar os mecanismos externos, descritos na literatura: sistema legal, mercado para o controle corporativo, auditoria externa, agências de rating (agências avaliadoras de risco), ativismo dos stakeholders e mídia (Aguilera et al., 2015).

No tocante a universidades, estes mecanismos se apresentam de outras formas, contudo, não se verifica na literatura atual artigos teóricos e empíricos que abordem estes conceitos. Diante disso, a seguir apresenta-se os conceitos de cada mecanismo e a conexão com universidades, em especial sem a finalidade de lucro.

\section{Sistema legal}

Para Bueno, et al. (2018), o primeiro mecanismo externo é o sistema legal, que trata de uma série de estruturas e processos utilizados para garantir o cumprimento da lei. Ele estabelece como os direitos de propriedade e as regulações são definidas e cumpridas: são as normas e os princípios estabelecidos nas bolsas de valores, nas instituições, nos grupos de interesse e na sociedade (Aguilera et al., 2015).

Todavia este mecanismo parece não estar bem definido para as organizações sem fins lucrativos. Conforme Mendonça e Machado Filho (2004), o sistema político-legal e regulatório, baseado em um marco legal genérico e com poucas ferramentas práticas de fiscalização, ainda está longe de criar um mecanismo efetivo para monitorar o comportamento gerencial dentro das organizações sem fins lucrativos.

De acordo com Mendonça (2003), no Brasil, em particular, o marco regulatório no qual se insere o Terceiro Setor passou por mudanças importantes num passado recente com a promulgação da Lei n 9790/99 das Organizações da Sociedade Civil de Interesse Público (OSCIP), que enquadra as pessoas jurídicas sem fins lucrativos. Essa lei representa importante avanço no marco 
regulatório, pois prioriza a transparência e valoriza o papel do conselho fiscal, das auditorias externas e da adoção de práticas administrativas que visam coibir o conflito de interesses.

Por outro lado, conforme Silva Jr (2006), a educação brasileira é um dos setores produtivos mais regulamentados pelo Governo Federal. Essa regulamentação está associada ao papel do Estado como agente regulador e corresponsável pela prestação de serviços educacionais (já que a oferta desses serviços também é facultada à iniciativa privada por autorização do poder público). O Estado Brasileiro, por meio dos poderes legislativo, judiciário e executivo, cada um em sua esfera de atuação, tem o papel de legislar, de julgar, de desenvolver e implementar políticas públicas para a educação superior. Ao desempenhar seu papel regulador, o Estado cria um sistema de normas e regras que determinam quem pode e quem não pode atuar no setor, a forma como cada agente deve atuar, suas responsabilidades, seus direitos, enfim, tudo o que se relaciona à atuação nesse setor produtivo e econômico.

\section{Mercado para o controle corporativo}

O segundo mecanismo externo é o de mercado para o controle corporativo, utilizado quando o valor da firma fica muito distante do valor que ela deveria ter de mercado (Bueno, et al.,2018). Para os autores, esse mecanismo é baseado na lógica de que os mercados operaram, em parte, para disciplinar os gestores e os conselhos de administração. A eficácia do mercado para as empresas é embasada em incentivos administrativos. Na visão de Mendonça e Machado Filho (2004), nas empresas privadas, os mecanismos institucionais reguladores e o próprio mercado, ainda que imperfeitos, têm papel disciplinador, ou seja, a ineficiência da gestão pode refletir-se nos preços das ações no mercado; em função disso, os principais têm forte incentivo para monitorar as atividades do

\section{Gestor e o destino de seus recursos}

No Terceiro Setor essa possibilidade é inexistente. 0 mercado de capitais das organizações sem fins lucrativos é representado pelo mercado de doações, o qual se baseia na liberdade dos doadores para direcionar seus recursos à organização que escolherem (Mendonça e Machado Filho, 2004).

Ressalta-se que uma universidade constituída na forma de uma fundação sem fins lucrativos não possui proprietários, porém possui instituidores, que através de uma escritura pública fazem uma dotação especial de 
bens livres, especificando o fim a que se destina. Após lavrada a escritura, elabora-se o estatuto social, que deve ser aprovado pelo ministério público. Dessa forma, fica a fundação sempre velada pelo ministério público, devendo prestar contas a este sempre que solicitado, tornando-se tal órgão um importante stakeholder. Ademais, o código de boas práticas de GC (para organizações do terceiro setor: associações e fundações) define que a denominação da entidade esteja desvinculada dos instituidores ou patronos, que seus objetivos sejam claros e explícitos, e que cumpra fielmente as legislações pertinentes, principalmente no que tange as prestações de contas intrínsecas a uma fundação (IBGC, 2016).

\section{Auditoria externa}

Moore, et al. (2006) citam a falta de independência dos auditores externos americanos como um dos fatores chave para a série de escândalos financeiros no final da década de 90 e início da seguinte. Os autores destacam que entre os mecanismos identificados como solução para aumentar a transparência na relação gestão - investidor está a auditoria independente. Sua finalidade é, através de uma averiguação imparcial e com reconhecida capacidade técnica, avalizar as demonstrações financeiras.

Para Bueno, et al. (2018), os auditores externos é o terceiro mecanismo, em que os controladores mitigam o problema de expropriação do minoritário, contratando uma auditoria externa de grande reputação. A finalidade da auditoria externa é expressar uma opinião externa, indicando que (1) as demonstrações financeiras, como um todo, são livres de distorções relevantes, seja devido a fraude ou a erro, e que (2) eles são apresentados de forma justa, de acordo com as normas de contabilidade vigentes.

Neste tópico, o IBGC (2016) recomenda que a estrutura administrativa das instituições sem fins lucrativos seja composta por um conselho curador, uma diretoria executiva e um conselho fiscal, sendo fundamental a adoção de uma auditoria independente.

\section{Agências de rating}

O quarto mecanismo externo são as agências de rating, que têm o papel de reduzir a assimetria de informação entre agentes e acionistas, oferecendo melhores informações acerca do desempenho da empresa e de 
suas práticas de governança (Bueno, et al.,2018). Tal mecanismo está diretamente relacionado a organizações com finalidade de lucro e, portanto, não está associado a governança de universidades sem fins lucrativos.

\section{Ativismo de stakeholders}

O quinto mecanismo externo de governança é o do stakeholder ativista, que reflete a pressão externa por políticas e práticas da empresa (Bueno, et al.,2018).

Para os autores, são dois os motivos que levam ao ativismo do acionista: o financeiro e o social. Nas duas formas, os ativistas têm conseguido influenciar a governança das empresas em que atuam. Segundo Lee, Mcnamara e Koo (2019), os acionistas percebem maior incerteza quando uma empresa experimenta um evento ativista. Além disso, o efeito de uma campanha ativista sobre o nível de incerteza dos investidores é moderado pela experiência prévia de ativistas e as táticas que eles usam.

Conforme Punsuvo, Kayo, e Barros (2007), para compreender o surgimento do movimento de ativismo dos investidores, é importante introduzir as razões históricas para o despertar da governança corporativa, com atenção específica para os conflitos de agência que surgem naturalmente no ciclo de vida das empresas.

Os autores destacam que as empresas nascem, em grande parte, como resultado de uma ação de seus fundadores, os quais acumulam, inicialmente, as funções de proprietários e gestores. 0 processo de evolução natural sugere que, obtendo sucesso, a empresa tende a crescer e, com o passar dos anos, a sucessão de comando na empresa deverá ocorrer. Em algum momento futuro, a separação da propriedade e gestão deverá ocorrer, incorporando na organização cada vez mais acionistas afastados da administração diária dos negócios.

Os desdobramentos do processo de evolução da empresa poderão ensejar a abertura de capital, contribuindo para a dispersão crescente da propriedade, como em mercados como dos Estados Unidos e Reino Unido, países berços da moderna governança corporativa.

Como resposta a esses conflitos, os investidores institucionais passaram a assumir uma postura mais ativa na condução de relações com as empresas nas quais detinham participação acionária. Gillan e Starks (1997), 
em pesquisa desenvolvida sobre o movimento do ativismo, apresenta o entendimento de que o ativismo do acionista pode ser observado como uma sequência contínua de reações ao desempenho das empresas.

Punsuvo, Kayo, e Barros (2007) destacam que embora o ativismo venha, muitas vezes, em resposta a fracos desempenhos da empresa, alguns estudos sugerem que nem sempre o ativismo possibilita uma recuperação.

\section{Mídia}

Para Bueno, et al., (2018), o sexto mecanismo externo de GC, a mídia, pode influenciar as ações da empresa em relação a sua adequação a melhores práticas de GC. Segundo Laruccia et al. (2012) o desenvolvimento de uma organização está diretamente ligado à utilização correta de novas ferramentas disponíveis no mercado. Em especial, as mídias oferecem diversas maneiras eficazes de promover o crescimento competitivo de uma empresa no mercado, tanto no seu meio externo quanto no interno.

Mais recente, os mecanismos de GC de ativismo e mídia, em especial a mídia por meio de redes sociais via internet tem ganhado destaque da academia. Segundo Luo, Zhang e Marquis (2016), o desenvolvimento do ativismo via Internet fornece um novo mecanismo de pressão de resposta incorporado nas sociedades. Os autores destacam que o ativismo via Internet é disperso, em movimento rápido e interativo, e, portanto, pode efetivamente concentrar atenção pública e potencialmente prejudicar a imagem externa de uma empresa através da geração de comparação social.

No Brasil, a temperatura do debate público com a participação de CEOs subiu nas últimas eleições presidenciais. Mas a tradição de ativismo vem de longa data - destaca-se a trajetória de Fabio Barbosa no Real/ABN e, mais recente, de Luiza Trajano à frente do grupo Mulheres do Brasil, assim como a de Cândido Bracher, do Itaú, em seus posicionamentos sobre educação. No exterior não faltam presidentes que tratam de assuntos muito além dos números: mudanças climáticas, equidade, inclusão, diversidade e causas sociais são alguns temas no topo da agenda (Harvard Business Review, 2019).

O uso da Internet por ativistas nas últimas duas décadas fornece algum potencial para enfrentar este desafio. Comparado com a mídia tradicional, a Internet é muito mais difícil de regular. Mídias sociais e comunicação digital reduz significativamente os custos na participação em ação coletiva (Kollock, 1999). 
Luo, Zhang e Marquis (2016) destacam que a velocidade é, portanto, essencial para antecipar-se ou alterar uma impressão pública negativa. Algumas empresas, por causa das suas características específicas, podem ser mais vulneráveis a comparação social e a danificar a imagem pública.

Neste contexto, as características de uma universidade podem ampliar os efeitos desse mecanismo de governança corporativa, em especial pela forma e modelo de gestão, objetivos institucionais, e debate critico por parte de alunos sobre questões sociais e políticas.

Embora a era das revoluções estudantis possa ter terminado há mais de meio século, os estudantes continuam atuantes na política, sendo muitas vezes a principal força nos movimentos políticos voltados às mudanças sociais em todas as partes do mundo. Talvez não mais estejam no centro dos movimentos políticos, no entanto são muitas vezes participantes indispensáveis, que frequentemente ajudam a moldar as mensagens, ideologias e táticas dos movimentos de protesto (International Higher Education, 2014).

Apesar do ativismo contínuo e do impressionante (porém muitas vezes ignorado) êxito, o movimento estudantil não tem recebido a atenção acadêmica que já teve no passado. Pode ser porque os movimentos originados no campus muitas vezes se moverem rapidamente para fora, para as ruas, envolvendo assim muitos outros segmentos da sociedade (International Higher Education, 2014).

Em conclusão, com base na revisão teórica realizada, apresentase as características da teoria da agência, dos mecanismos de governança corporativa e da gestão em universidades sem fins lucrativos. (Quadro 2).

Quadro 2. Características desenvolvidas nos estudos de governança e IES

\begin{tabular}{lll}
\hline \multicolumn{1}{c}{ Teoria da agência } & Mecanismos de governança & \multicolumn{1}{c}{$\begin{array}{c}\text { Caracteristas de IES } \\
\text { sem fins lucrativos }\end{array}$} \\
\hline - Agente e principal. & - Sistema legal. & - Sistema legal e regulatório. \\
- Acionistas e adminis- & - Mercado para o controle & - Divergência de opiniões. \\
tradores. & corporativo. & - Grupos de interesse. \\
- Conflitos. & - Auditoria externa. & - Estrutura da entidade mante- \\
- Assimetria de infor- & - Agências de rating. & nedora e mantidas. \\
mações. & - Ativismo. & Ativismo pela comunidade \\
& - Mídia. & acadêmica. \\
& & - Recursos próprios
\end{tabular}

Fonte: elaborado pelos autores, 2020. 
Embora as pesquisas sobre a teoria da agência desenvolvam os conflitos e assimetria de informações entre acionistas e administradores, considerando as características das universidades, este estudo propõe a utilização deste aparato teórico para a gestão destas instituições, seja pela semelhança de aspectos de gestão, controle e propriedade, seja pela existência de conflitos e assimetria de informações.

Diante dos estudos apresentados, fica evidente a importância de pesquisas para buscar as melhores práticas e teorias, contribuindo com a governança de instituições de ensino sem fins lucrativos. A seguir apresentase os mecanismos de governança corporativa aplicados para organizações em geral e a indicação dos mecanismos para as universidades sem fins lucrativos - com base no referencial teórico e análise das pesquisas que tratam a governança corporativa para IES - (Figura 3).

Figura 3. Mecanismos de governança corporativa

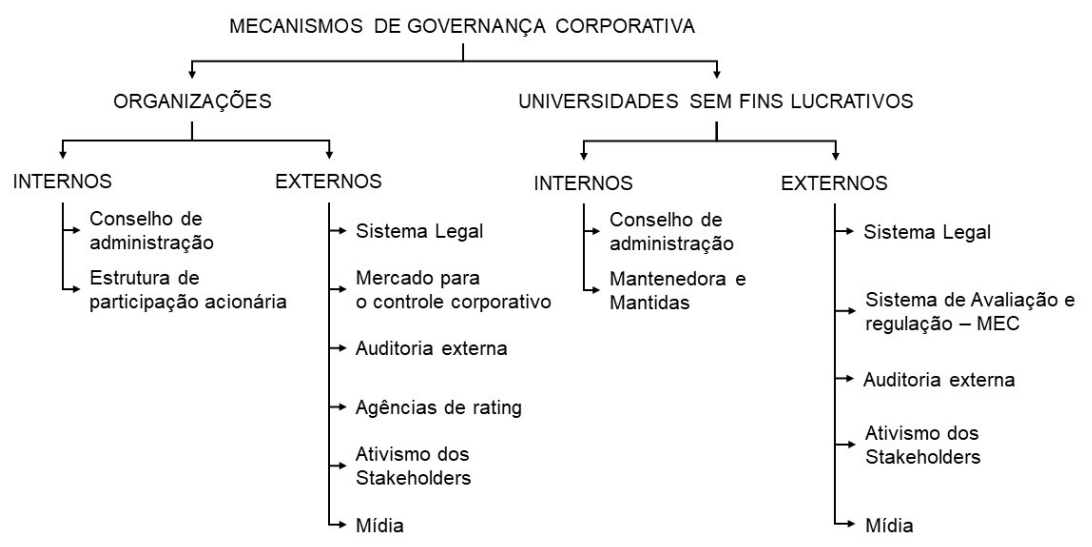

Fonte: elaborado pelos autores, 2020.

Com base na teoria analisada, em síntese, é possível apresentar os mecanismos de governança corporativa. O sistema legal apresenta-se como um mecanismo externo de governança corporativa para universidades sem fins lucrativos face a robusta legislação existente e que regula o setor.

No Brasil, cabe ao Sistema Nacional de Avaliação da Educação Superior (SINAES) avaliar a "eficácia institucional das IES e a sua efetividade acadêmica e social (Inep, 2017). Segundo Bonisenha e D'Angelo (2018), a eficácia institucional na educação pode ser entendida como o cumprimento de objetivos e metas pedagógicos da IES; tem uma natureza intrínseca à IES. Já a efetividade acadêmica e social pode ser entendida como os impactos e transformações sociais ocorridos e expectativas alcançadas. 
Mesmo sem a finalidade de lucro, as universidades na forma de fundações, por força de legislação própria necessitam de auditoria externa, sendo este um mecanismo existente no mercado da educação. Aqui cabe destacar o papel do Ministério Público como ente fiscalizador das fundações sem fins lucrativos. Destaca-se também a necessidade de auditoria externa pela participação das universidades em editais públicos e convênios com entidades públicas e privadas.

0 ativismo de stakeholders destaca-se como um mecanismo externo de governança corporativa para uma universidade sem fins lucrativos. Conforme já constatado em organizações de forma geral, uma boa governança pode diminuir a necessidade de iniciativas ativistas. Vargas et al. (2018) encontraram menor ativismo em empresas com melhor governança. No setor educacional este mecanismo é intensificado pela visão crítica de estudantes e professores do ensino superior seja pelo ambiente propicio ao debate, seja pela diversidade de opiniões e saberes produzidos em uma universidade.

Por fim, a mídia configura-se como um mecanismo externo de governança na medida em que os impactos - positivos e negativos - de ações e projetos influenciam na sociedade e no campo de atuação das universidades.

\section{Conclusão}

Este artigo teve como objetivo compreender a dinâmica dos mecanismos de governança corporativa para as universidades sem fins lucrativos. Por meio do levantamento dos estudos na área, foi possível verificar em primeira análise que o tema governança corporativa no contexto de IES e para universidades sem fins lucrativos é incipiente, faltam estudos que desenvolvam os mecanismos de GC no segmento do ensino superior. Por outro lado, é possível observar a existência deste fenômeno nas universidades sem fins lucrativos, seja pela complexidade na gestão, - ambiguidade dos objetivos, grupos de interesse, poder compartilhado - seja pela forma e estrutura de propriedade mantenedora e mantidas - que confere novos formatos e relações de agência.

Do ponto de vista gerencial no processo de gestão universitária, a mantenedora e a mantida tomam decisões conjuntas e isoladas. As decisões de natureza estratégica, via de regra, são tomadas conjuntamente, pois envolvem questões de natureza jurídica, administrativa, financeira e acadêmica, ou seja, envolvem interesses da estrutura de propriedade e de direção. Todavia, as decisões ocorrem em grupos de interesse distintos ocasionando conflitos de agência. Do ponto de vista teórico, a teoria da agência desenvolve a relação (conflitos) entre principal (proprietário, acionistas) e agente (gestores), en- 
tretanto, no contexto das universidades sem fins lucrativos contata-se, além do conflito principal - agente a existência, e maior propensão de conflitos agente - agente. Embora ocorra a existência da mantenedora e mantida, as decisões não seguem padrões definidos, neste sentido a perspectiva de governança corporativa para universidades é mais ampliada do que a simples relação entre a propriedade e a direção, trata-se de uma perspectiva para resguardar os interesses institucionais e dos stakeholders.

Neste contexto, este artigo buscou discorrer sobre os mecanismos internos e externos de governança corporativa com enfoque na gestão de universidades sem fins lucrativos tendo como base o aparato teórico analisado. Embora não tenham muitos estudos sobre mecanismos de GC, pode-se verificar a relação destes no contexto das universidades sem fins lucrativos, com destaque para o ativismo e a mídia digital que segundo Luo, Zhang e Marquis (2016), fornece um novo mecanismo de pressão de resposta incorporado nas sociedades. Estudos futuros - teóricos e empíricos -, poderiam trabalhar estes mecanismos de governança e a influencia na gestão e adaptação estratégica das IES e universidades sem fins lucrativos.

\section{Referencias}

Aguilera, R.V., Desender, K., Bednar, M.K., e Lee, J.H. (2015). Connecting the Dots - bringing external corporate governance into the corporate governance puzzle. The Academy of Management Annals, 9(1), 483-573.

Amarante, J.M., Crubellate, J. M. e Meyer JR, V. (2016). Estratégias em Universidades: uma análise comparativa sob a perspectiva institucional. Revista Gestão Universitária na América Latina - Gual, 10(1), 190-212.

Andrade, A. e Rossetti, J.P. (2007). Governança corporativa: fundamentos, desenvolvimento e tendências. São Paulo: Atlas.

Arruda, G.S., Madruga, S.R. e Freitas Junior, N.I. (2008). A governança corporativa e a teoria da agência em consonância com a controladoria. Revista de Administração da UFSM, 1(1).

Ávila, L.A.I. de, e Bertero, C. O. (2016). Governança no terceiro setor: um estudo de caso em uma fundação de apoio universitário. Revista Brasileira de Gestão de Negócios RBGN, 18(59), 125-144.

Baldridge, J.V. (1971). Power and conflict in the university. New York: John Wiley \& Sons.

BNDES, Banco Nacional do Desenvolvimento. (2001). Gerência de Estudos Setoriais - Geset. Terceiro Setor e Desenvolvimento Social: Relato Setorial № 3. Brasília: Bndes.

Bonisenha, C. N., e D'angelo, M. J. (2018). O Papel da Cultura Organizacional no Desempenho Operacional de uma Instituição de Ensino Superior à Luz dos Indicadores de 
Qualidade Sinaes. BASE - Revista de Administração e Contabilidade da UNISINOS, 15(4), 307-327.

Brandão, I. F. e Crisóstomo, V. L. (2015). Concentração de propriedade e qualidade da governança da empresa brasileira. Revista Brasileira de Finanças, 13(3), 438-438.

Bueno, G., Nascimento, K., Lana, J., Gama, M. A. B., \& Marcon, R. (2018). Mecanismos Externos de Governança Corporativa no Brasil. Revista Contabilidade, Gestão e Governança, 21(1), 120-141.

Canito, F.O.F., Tassigny, M.M. e Almeida, F.P.B. (2014). Possibilidades de efetivação de práticas de governança em fundações privadas. Revista Brasileira de Administração Científica, 5(3), 305-326

Daily, C. M., Dalton, D. R., e Cannella, A. A., Jr. (2003). Corporate governance: Decades of dialogue and data. Academy of Management Review, 28(3), 371-382.

Denis, D. K. (2001). Twenty-five years of corporate governance research....and counting. Review of Financial Economics, 10(3), 191-212.

Dzięgiel, A. e Wojciechowska, A. (2016). Social Responsibility in Intra-organizational Procedures of Higher Education Institutions with AACSB Accreditation. Journal of Corporate Responsibility And Leadership, Toru , Poland, 3(2), 23-50.

Eisenhardt, K. M. (1989). Agency Theory: An Assessment and Review. Academy of management review, 14(1), 57-74.

Flórez-Parra, J. M., López-Pérez, M. V., e López-Hernández, A. M. (2019). Corporate governance in Colombian universities. International Review of Administrative Sciences, 85(3), 544-565.

Gillan, S. e Starks, L. (1997). Relationship Investing and Shareholder Activism by Institutional Investors. Working paper, Austin: University of Texas.

Grings, P. F. e Vier, A. J. (2019). Governança corporativa em instituições de ensino superior privadas localizadas no Rio Grande do Sul. Revista Eletrônica do Curso de Ciências Contábeis, 9(2), 114-140.

Harvard Business Review (2019). Ativismo dos CEOs e benefícios para as marcas. Disponível em https://bit.ly/35QovrO.

Instituto Brasileiro de Governança Corporativa - IBGC. (2016). Guia das Melhores Práticas para Organizações do Terceiro Setor: Associações e Fundações. Disponível em: https:// bit.ly/3dB1ZVS.

Instituto Brasileiro de Governança Corporativa - IBGC. (2019). Código das melhores práticas de governança corporativa. Disponível em: <http:// www.ibgc.org.br.

Instituto Nacional de Estudos e Pesquisas Educacionais Anísio Teixeira (Inep). (2017). Sinaes. 0 que é o Sinaes. Disponível em: http://portal.inep.gov.br/sinaes. Acesso em: 13 jan. 2020.

International Higher Education (2014). Ativismo estudantil permanece como uma força poderosa em todo o mundo. Disponível em https://bit.ly/3cnCZkF.

Jensen, M. e Meckling, W. (1976). Theory of the firm: managerial behavior, agency cost, and ownership structure. Journal os Financial Economics, 305-360. 
Jung, H., Fossatti, P. e Marlon Monticelli, J. (2019). Profile of managers in brazilian Community Universities. Revista Educação em Questão, 57(54).

Kreuzberg, F. e Vicente, E. F. R., (2019). Para onde Estamos Caminhando? Uma Análise das Pesquisas em Governança Corporativa. Revista de Administração Contemporânea, 23(1), 43-66.

Kollock, P. (1999). The Economies of Online Cooperation: Gifts and Public Goods in Cyberspace, in Smith, M. A., P. Kollock. (eds) Communities in Cyberspace. Routledge.

Laruccia, M., de Jesus Rodrigues, A., de Medeiros Pereira, M. L., e de Oliveira, V. B. (2012). Ensaio sobre a importância das mídias sociais nas organizações. Caderno de Administração. Revista da Faculdade de Administração da FEA, 6(1).

Lee, J. J., McNamara, G. M. e Koo, H. (2019). Examining a Cost of Shareholder Activism: Heightened General Investor Uncertainty. In Academy of Management Proceedings (Vol. 2019, No. 1, p. 12868). Briarcliff Manor, NY 10510: Academy of Management..

Lopes, L. A. C. e Bernardes, F. R. (2016). Estruturas administrativas das universidades brasileiras. In: Seminários de Administração - SEMEAD, 15., 2005, São Paulo. FEA USP, 2005. Disponivel em https://bit.ly/2Wk5Qk4.

Luo, X. R., Zhang, J., e Marquis, C. (2016). Mobilization in the internet age: Internet activism and corporate response. Academy of Management Journal, 59(6), 2045-2068.

Mac Lennan, M. L. F.; Semensato, B. I., e Oliva, F. L. (2015). Responsabilidade Social Empresarial: Classificação das Instituições de Ensino Superior em Reativas ou Estratégicas sob a Ótica da Governança Corporativa. REGE - Revista de Gestão. São Paulo, v. 22, n. 4 , p. 457-472.

Meyer Jr., V. e Mangolim, L. (2006). Estratégia em Universidades Privadas. In: Estratégia em universidades privadas: estudo de casos. Encontro Anual da Associação Nacional dos Programas de Pós-Graduação em Administração (ENANPAD), 30.

Meyer Jr, V. e Lopes, M. C. B. (2015). Administrando o imensurável: uma crítica às organizações acadêmicas. Cad. Ebape.br, 13(1), 40-51.

Mello, M. da S. de, e Silva, R. de O. da. (2018). Práticas de governança corporativa em instituições de ensino superior: um estudo de caso em uma universidade de santa catarina. Revista de administração e contabilidade - RAC (CNEC), 33, 68-80.

Mendes, A. P. S. (2001). Teoria da agência aplicada à análise de relações entre os participantes dos processos de cooperação tecnológica universidade-empresa. Tese (Doutorado em Administração) - Faculdade de Economia, Administração e Contabilidade, São Paulo, SP, Brasil.

Mendonça, L.R. (2003). A decisão entre manter as práticas de atuação social vinculadas à estrutura organizacional ou constituir uma fundação ou instituto. Dissertação (Mestrado) - Faculdade de Economia, Administração e

Contabilidade da Universidade de São Paulo, São Paulo, São Paulo, Brasil.

Mendonça, L. R., Machado Filho, C. A. P. (2004). Governança nas organizações do terceiro setor: considerações teóricas. Revista de Administra\&ccdeil, 39(4), 302-308.

Moore, D. A., Tetlock, P. E., Tanlu, L., \& Bazerman, M. H. (2006). Conflicts of interest and the case of auditor independence: moral seduction and strategic issue cycling. Academy of Management Review, 31(1), 1-20. 
Mulili, B. M. e Wong, P. (2011). Corporate governance practices in developing countries: The case for Kenya. International journal of business administration, 2(1), 14.

Punsuvo, F. R., Kayo, E. K., e Barros, L. A. B. D. C. (2007). 0 ativismo dos fundos de pensão e a qualidade da governança corporativa. Revista Contabilidade \& Finanças, 18(45), 63-72.

Santos, A. P. dos. (2008). Governança corporativa e desempenho em instituições privadas de ensino superior: um estudo de caso em Minas Gerais. Revista de Contabilidade da UFBA, 2(3), 79-94.

Silva Jr, A. (2006). Trajetória de crescimento, governança corporativa e gestão universitária: estudo de caso em três instituições de educação superior do tipo familiar. Tese de Doutorado. Tese (Doutorado) Centro de Pós-Graduação e Pesquisas em Administração, Universidade Federal de Minas Gerais, Belo Horizonte.

Tavares, S. M. N. (2009). Governança em universidades confessionais no Brasil: modelo em construção. Educação \& Linguagem, 12(19), 219-238.

Taylor M. (2012). Governança compartilhada na universidade moderna. Higher Education Quarterly, 67, 80-94.

Vargas, L. H. F., Bortolon, P. M., Barros, L. A. B. C., e Leal, R. P. C. (2018). Recent activism initiatives in Brazil. International Journal of Disclosure and Governance. https://doi. org/10.1057/s41310-018-0035-1.

Vilela, A.L.N. (2016). Governança Corporativa em uma Instituição de Ensino Superior Privada: Um Estudo de Caso. Dissertação (Mestrado) - Curso de Mestrado em Sistemas de Gestão, Universidade Federal Fluminense, Niterói Rj, Brasil.

Vilela, A.L.N. e Veloso, L.H.M. (2014). Governança corporativa nas instituições de ensino superior. In: XIV Colóquio Internacional de Gestão Universitária - CIGU, dez, 2014, Florianópolis. Anais... Florianópolis.

Weston, J. F. e Brigham, E. (2004). Fundamentos da administração financeira. 10. ed. São Paulo: Pearson Makron Books. 